VIRTUAL CONSERVATION-RESTORATION VS. ACTUAL CONSERVATION-

RESTORATION IN THE CONSERVATION OF FRAGMENTARY ARTEFACTS: THE CASE

STUDY FRESCOES FROM SYBARIS - COPIA (ITALY)

MUCA Sokol ${ }^{1}$

${ }^{1}$ Student at the ISCR, Higher School of Conservation and Restoration of the Cultural Heritage, in Matera, Italy. His Supervisors: Maria Carolina Gaetani, ISCR, Conservator, and Giorgio Sobrà, ISCR, Architect, Director of the Higher School of Conservation and Restoration of the Cultural Heritage, in Matera. The Chief Supervisor is Giovanna De Palma, ISCR, Archaeologis

https://orcid.org/0000-0002-6715-5969

ABSTRACT: This article discusses the role that new digital technologies play on conservationrestoration of fragmentary artefacts. Above all, the use of these tools is essential in case the artefacts have lost the formal unity and reach us without documentation concerning their original position, as in the case of the Roman frescoes from Sybaris, object of this study. The creation of virtual models proves as fundamental for the material and formal recomposition of the artefacts, especially in the creation of a new support and display choices. This last aspect required an analysis on the effects that virtual reconstructions and augmented reality have on visitors.

KEYWORDS: 3D, Augmented Reality, perception, Virtual restoration, Roman frescos

\title{
Introduction
}

Some Roman age fresco fragments, detached from a domus within the ancient city of Sybaris - Thurii Copia, nowadays part of the Archaeological Museum and Site of the Sybaritis (Italy). They underwent in-depth study and conservation works during the didactic activities held at ISCR Laboratories in Matera, in the academic year 2016-2017. The finds were unearthed in 1962 in an excavation area called Parco del Cavallo. Due to a flood which affected the site in October of 1971 it was necessary to detach the frescos in order to preserve them. The procedure was carried out by a team of ISCR (at that time 
ICR) experts ${ }^{1}$. The fresco fragments were gathered in five panels and sent to the labs in Matera.

However, the documentation on their original position was incomplete. Moreover, due to their fragmentary nature it was difficult to get either a formal or a stylistic knowledge.

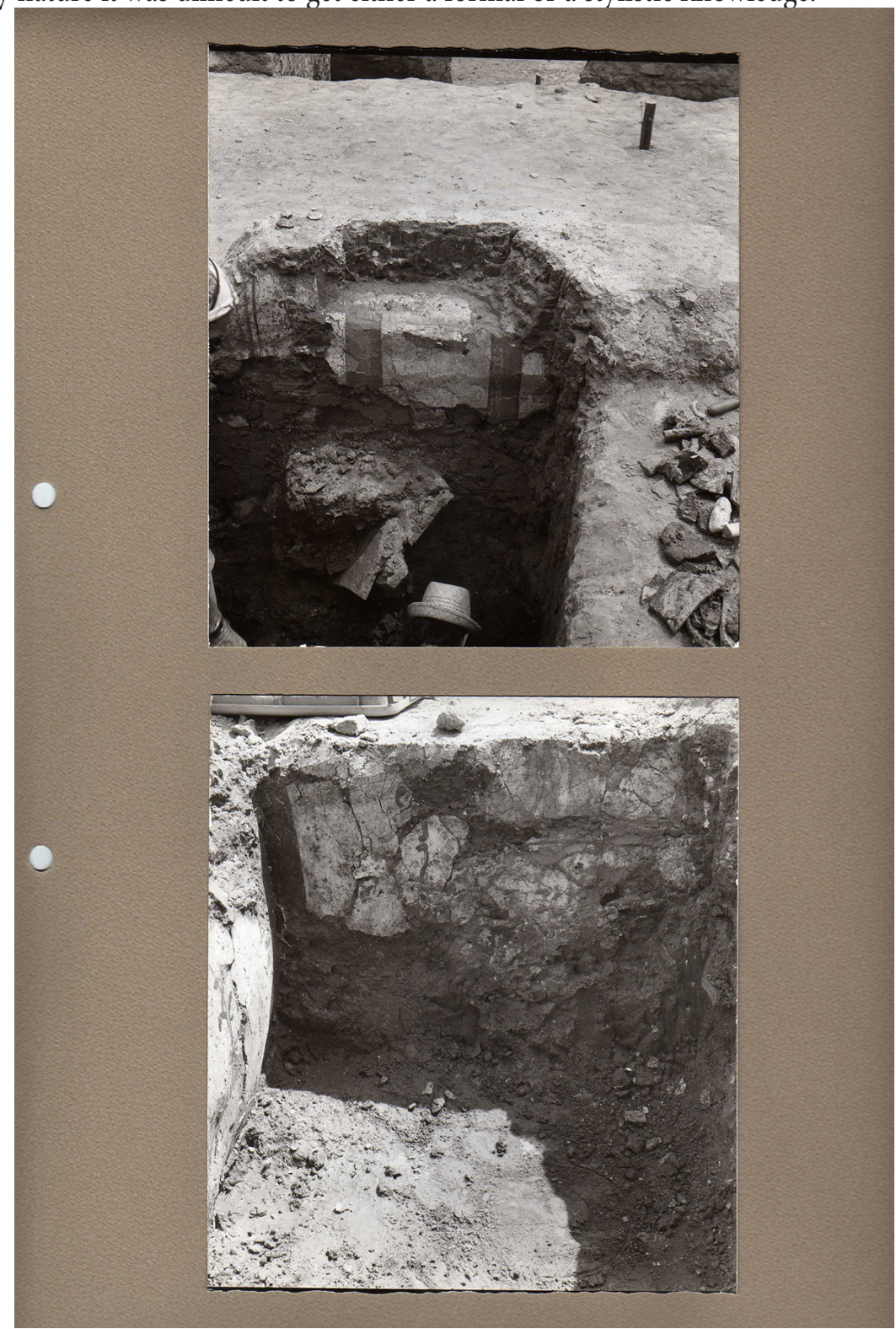

Fig. 1 Photo taken during the 1962 excavation campaign (Photo credit: ISCR archives)

1 The archaeologist Licia Vlad Borreli, the conservator Giuseppe Moro and the chemist Marisa Tabasso led the operation; the urgency to act is evident in the correspondence between the "Soprintendenza delle Antichità della Calabria" and ICR. The documents are nowadays kept in the ISCR archives. 


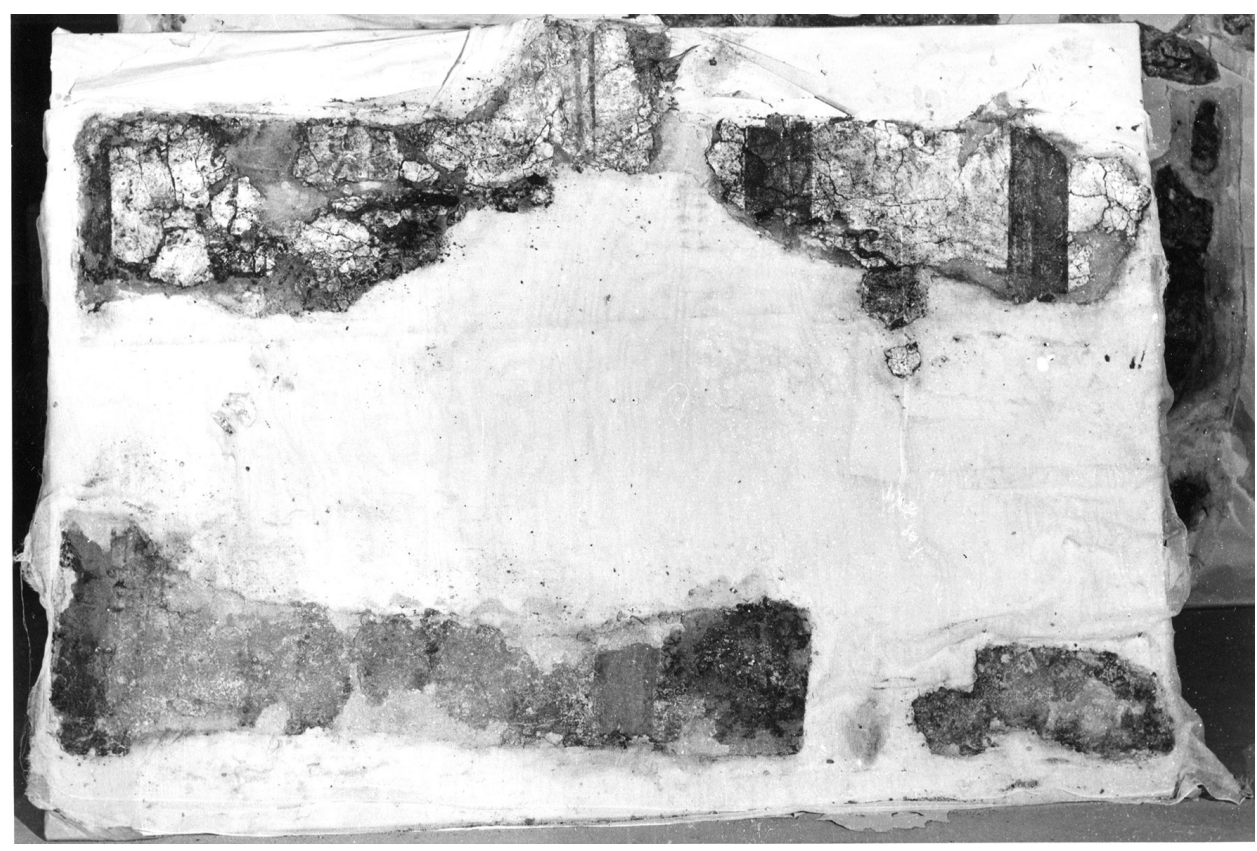

Fig. 2 Photo after the detachment (Photo credit: ISCR archives)

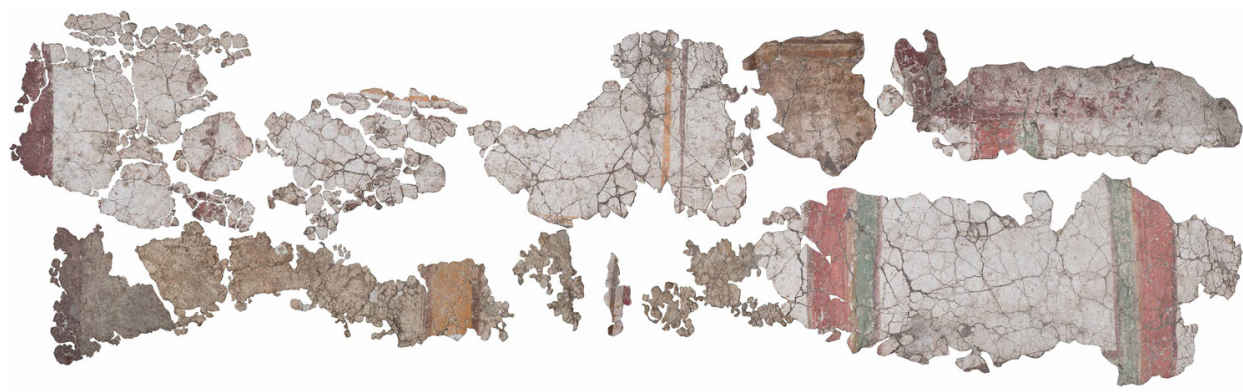

Fig. 3 State of conservation of the fragments before restoration (Photo Credit: Angelo Rubino, ISCR)

The conservation-restoration work, the completion of the cleaning in particular, brought to light new details that made it possible to put forward hypotheses about the decoration. 


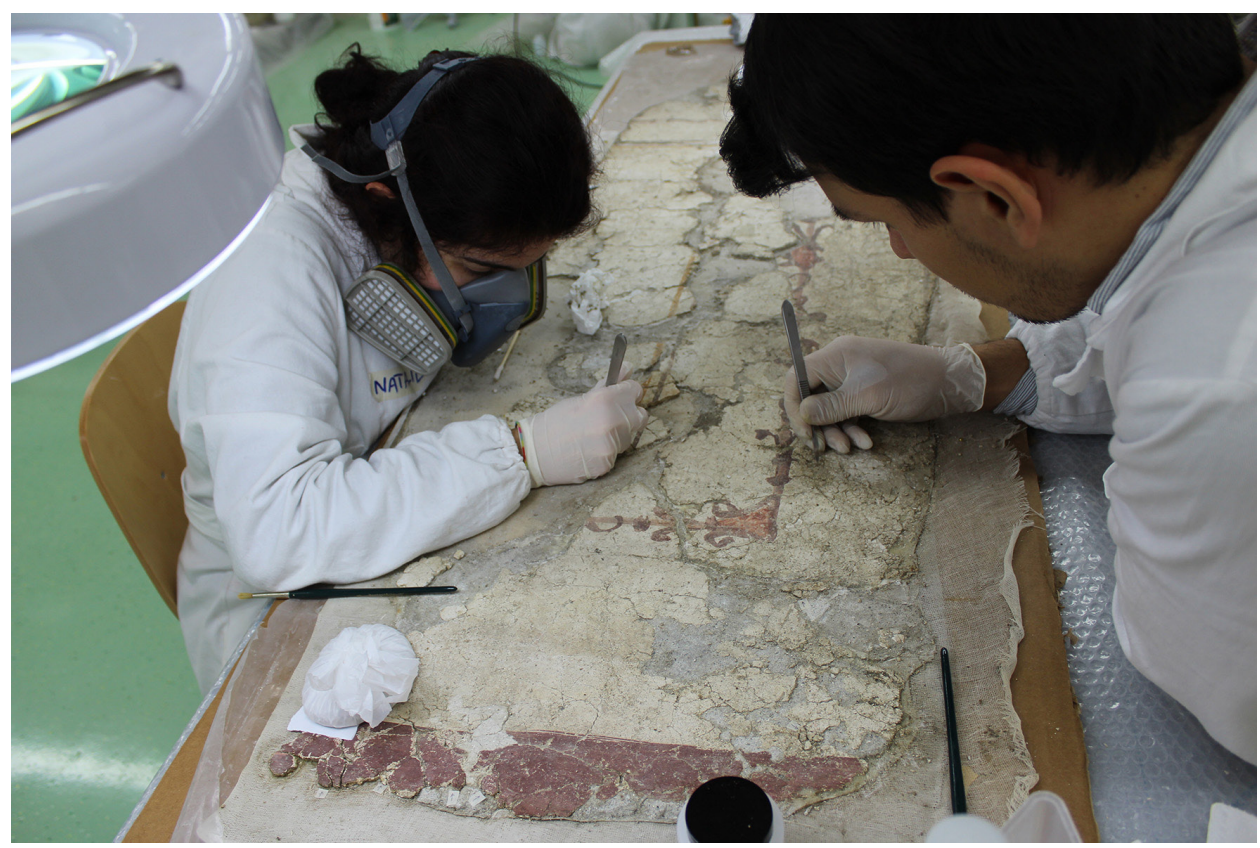

Fig. 4 Matera, ISCR laboratories, Working on the frescoes fragments (Photo Credit: Sokol Muca, ISCR-Matera student

The analysis of the execution techniques, of the constitutive materials and of the state of conservation of the fragments, together with the iconographic and documentary study led to the creation of a virtual model which aims at investigating and integrating the conservation-restoration work along with educational and didactic purposes. The realization of the 3D model of the frescoed environment was dictated not only by divulgation aim but above all knowledge. Virtual conservation-restoration has not only been seen as an ideal reconstruction modality of the artefact but also as a methodology for the checking and synthesis of analytical data. The virtual model represented the last link in a chain of studies that are intended as a point of convergence and method for the data verification. The 3D reconstruction has helped the knowledge of the artefact obtaining significant increases in the quality of information. The lack of integrity caused difficult iconographic problems: the information collected through the in-depth observation, the direct contact with the objects and the thorough knowledge of the artefacts have been important tools to speculate about the correct reconstruction.

\section{Decorative model}

The frescoes come from a residential room with decorations on the four walls, depicting geometric figures and vegetal ornaments typical of Roman wall paintings. 


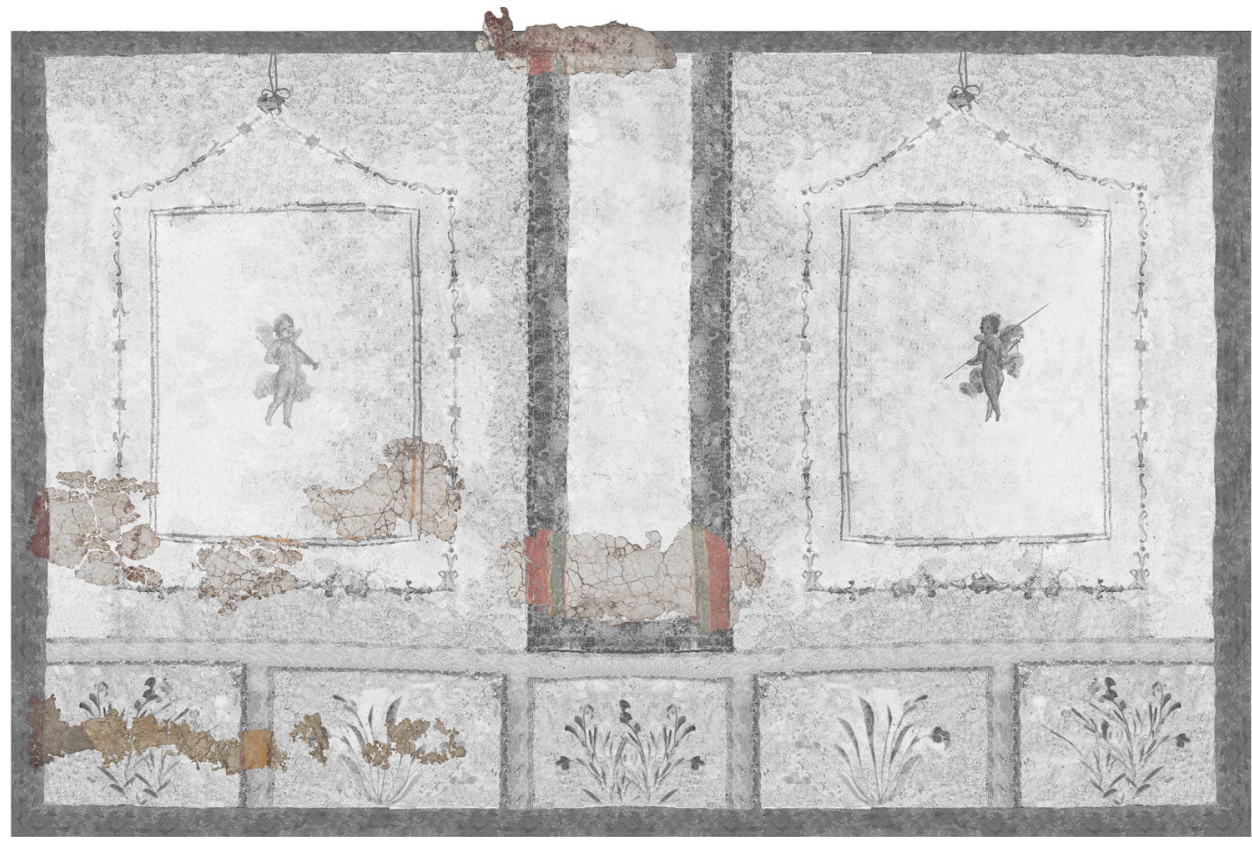

Fig. 5 Hypothesis of the decorative model (Author of the sketch, Sokol Muca, ISCR-Matera student)

The room has two long walls and two shorter ones. The decoration on a white background was organized on three horizontal bands. A frame of red morellone $e^{2}$ delimited the edges of the wall and in the lower level there were squares divided by yellow-morellone stripes within which vegetal motifs were painted. The intermediate register, on the shorter wall, is decorated with the succession of two panels with vegetable branches, inside which are smaller panels made of a double line in morellone and yellow. The panels are separated by a vertical element, similar to a simplified aedicula made of three colour bands: morellone, yellow and green. Where the short walls of the room were probably composed of two panels and one aedicula, the longer wall should be formed by the sequence of three panels and two aedicula. Architectural motifs must have been painted on the upper level, as it was common at the time. However, since only the lower part of the wall was preserved, the reconstruction of the decoration on the upper band is the result of stylistic comparisons with other surviving works especially with the ones from Herculaneum and Pompei.

After the photogrammetric survey, the reconstruction of the 2-D composition module was processed using appropriate software and to re-stitching the missing parts.

\footnotetext{
2 "Intense Red, Red ochre + coal black, used in Roman frescoes as ground layer for blue sky iron, oxide, hematite type, Red, "this is the synthetic equivalent of the naturally occurring mineral, hematite $\mathrm{Fe} 2 \mathrm{O} 3$, which produces a bright red pigment. Being a stable compound, it may be produced by many methods. These are described in Cornell and Schwertmann (1996) and may be summarised as follows": Eastaugh et al. 2004, p. 201.
} 


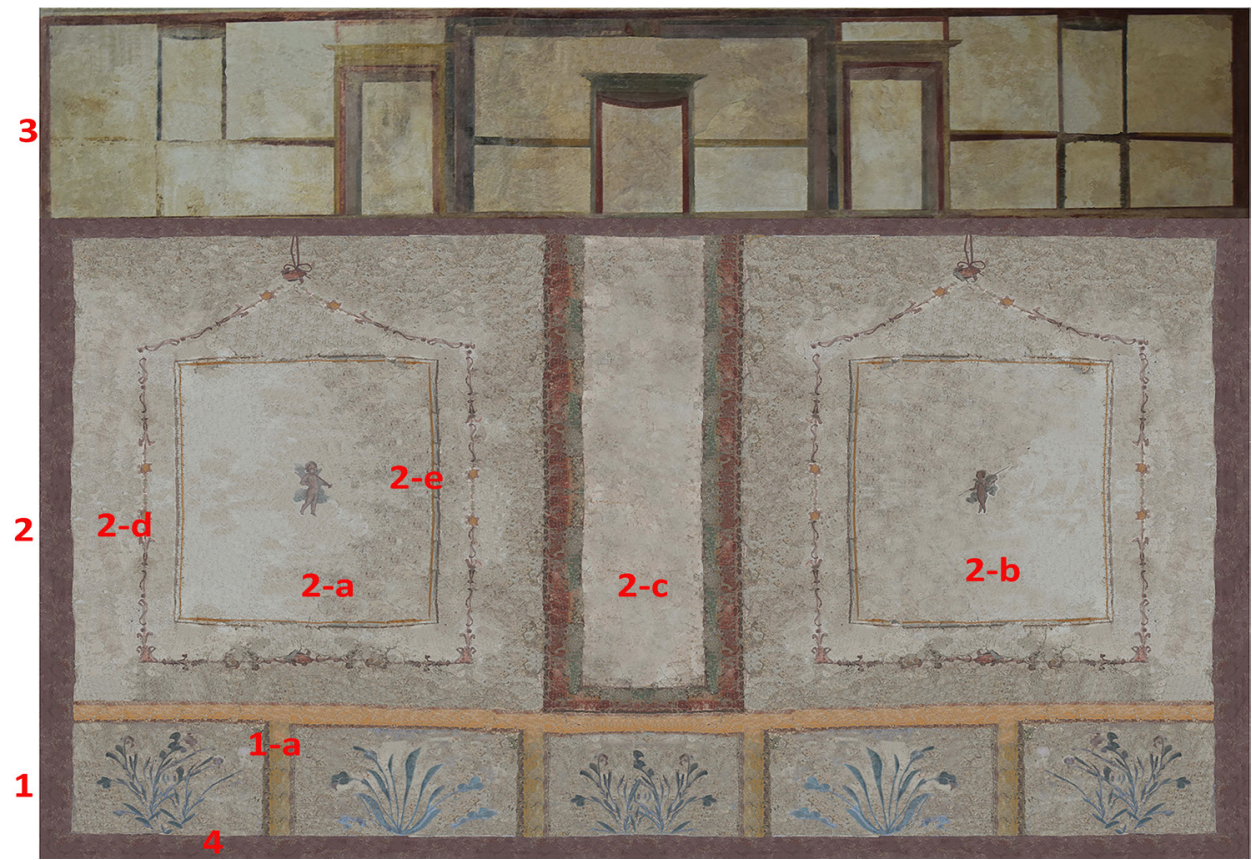

Fig. 6 Virtual Restoration of the west Wall. 1, 2, 3, three horizontal bands. (4) a frame of redmorellone delimited the edges of the wall. (1-a) Yellow- morellone stripes and vegetal motifs. (2- a, b) two panels with vegetable branches, inside which are smaller panels made of a double line in morellone and yellow (2-d, e). (2-c) a vertical element, similar to a simplified edicula made of three colour bands: morellone, yellow and green (Author of the sketch, Sokol Muca, ISCR-Matera student)

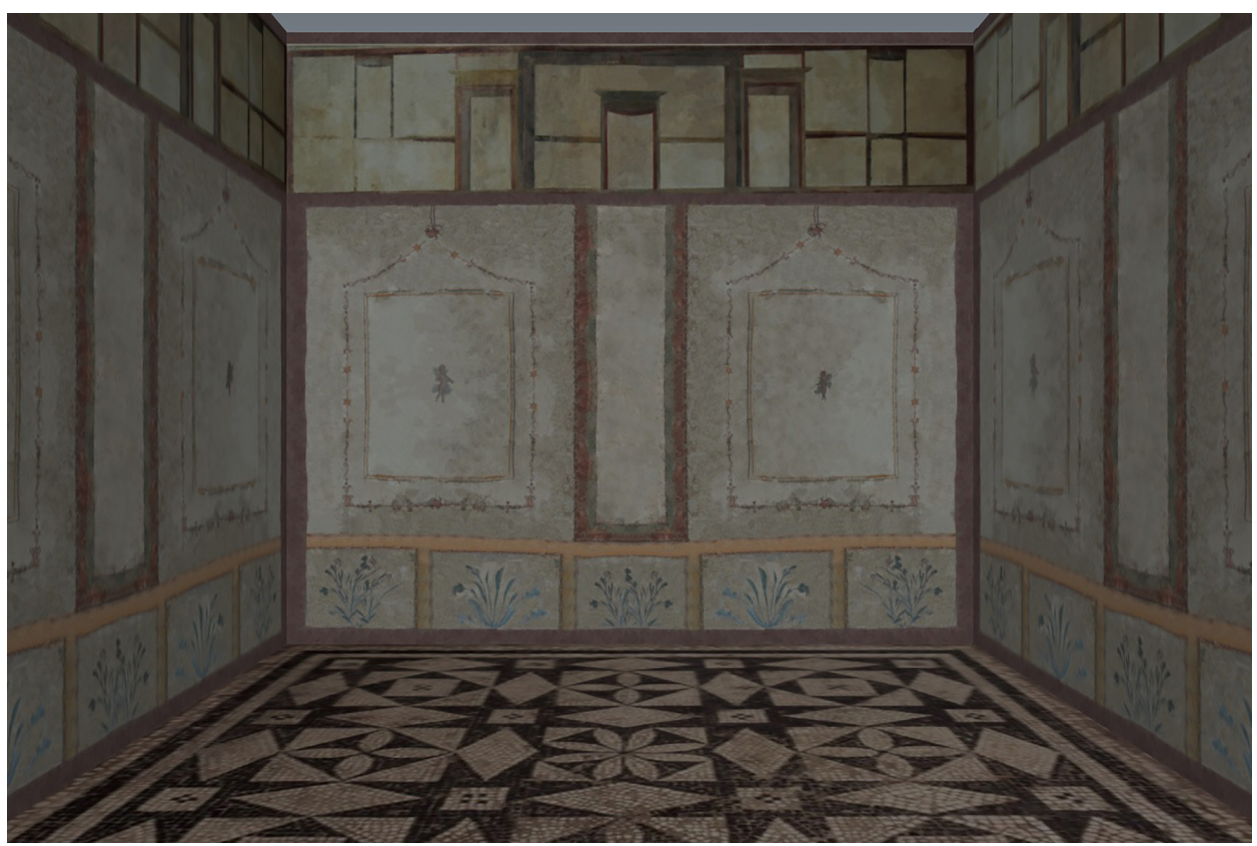

Fig. 7 3D reconstruction hypothesis of the Domus of Copia environment, Archaeological Park of Sybaris, area 70 (Author of the sketch, Sokol Muca, ISCR-Matera student) 
Once the parietal module was obtained after synthesizing all the information, the 3-D virtual model of the environment was carried out. This allowed us to make some checks on the metric relationships and to put aside other hypotheses. The application of the texture on the 3-D model allowed us to visualize the ambience as it must have been: a sumptuous room decorated with frescoes and a mosaic floor.

\section{Virtual Conservation-restoration, limits and benefits}

The virtual reconstruction allows to see the artefact as it was meant to be, recovering the lost formal values. It was then possible to develop a virtual model that would optimize the readability of the artefacts, collecting data during the conservation-restoration work and integrating them with archive data. During the process of virtual reconstruction, it was necessary to adopt the same principles Cesare Brandi suggested for the actual conservation-restoration in order to avoid interpretative mistakes, although working on digital information had the advantage of modifying, duplicating and deleting data without any consequences or damage to the artefact. (Brandi [1963] 1977 and 2005) Like the integration on real artefacts, also virtual integration has to comply with the concept of authenticity ${ }^{3}$ too, differentiating the integrated parts from the original ones. The technological means offer the opportunity to perform virtual conservation-restoration, which allows the analysis and the comparative assessment of the different hypotheses before carrying out any action directly affecting the artefacts. Moreover, we can choose the most efficient option of reconstruction of the lost or modified parts. In this regard, the reconstruction purpose must check complex information, test hypotheses, analyse and interpret specific aspects, display formal data that would not be easily examined in the real context as well as define and increase the aims of the conservation work.

\section{Conclusions}

This study was aimed at understanding the role that virtual reconstruction plays in the field of cultural heritage, based on a critical interpretation of the contents, whose primary objective is to set up a debate, among all the people who deal with cultural heritage on the need to apply digital technologies and visualization methods with scientific and intellectual rigour. Although today we are witnessing renewed technological enthusiasm for the issues related to conservation-restoration and the consequent inclination to welcome the available scientific tools as miraculous and unquestionable, the use of technological facilities requires greater carefulness, and above all thorough knowledge integration. We must share the difficulty in finding consistency in the field of conservation-restoration. The wide range of experiences and the consequent difficulty in reaching the right solution in this field, has allowed us to make a reflection on the need to suggest specific guidelines on virtual reconstructions for cultural heritage. The use of these tools is not to be excluded immediately, because the opportunity of carrying out reconstructions, as far as it is legitimate, is supported by a further remark: any intervention is still an action taken in the present with which, intervening on the lost text, we fix a new ratio of values between the existing elements and the missing ones and, in a broader sense, between the artefact

\footnotetext{
3 "Accordingly, the second principle of restoration can be stated: Restoration should aim to re-establish the potential oneness of the work of art, as long as this is possible without committing artistic or historical forgery, and without erasing every of the passage through time of the work of art." Brandi [1963] 1977, quoted from the English translation 2005, p. 50.
} 
and its history. Moreover, virtual reconstructions can be auxiliary means to help the public deepen their knowledge of cultural heritage and set out approaches based on multi-sensorial perceptions and on the active involvement in the exploration of contents, with the aim of raising the curiosity, the interest and affection of the public for cultural heritage, so as to spontaneously trigger actions of care, preservation, knowledge and enhancement.

The rules on the use and application of technologies for virtual reconstruction have already been defined and organized with rigorous methodological principles. The London Charter ${ }^{4}(2009)$ and the Seville Charter $^{5}$ (2011) have already dealt with the aspects above mentioned. Since the methodological procedure has been systematically defined, we will focus on the impact they have on the public. It is now clear that the systematic use of 3-D reconstructions, Virtual Conservation-restoration and Augmented Reality are deeply modifying our perception of reality in the fruition of cultural heritage. The display panels with textual explanations certainly provide the information necessary to understand the history, the formal, material, technological and social aspects as well as the various transformations in time. This contributes to situate images in a specific cultural context. But our attention is being increasingly attracted by amazing reconstructions that may have the drawback of pushing the artefacts in the background. The studies conducted on visual perception by Rudolf Arnheim ${ }^{6}$ (Arnheim1954) and Ernest Gombrich (Gombrich 1982) exhaustively described our inclination to prefer a complete image because our brain perceives them as 'order', unlike fragmentary images which are perceived as 'disorder.' The complete images reconstructed, on the one hand, it reduces the chance of interpretative misunderstandings that may arise with extremely fragmentary artefacts, but on the other hand it reduces the level of study in deep. Every reconstructive hypothesis therefore implies the redefinition of the artefact. Every reconstruction brings us closer to the original integrity and completeness of interpretation that time has taken away. On the contrary, the artefact that has not recovered its integrity keeps in itself the stratification of history and needs to be decoded. The perception of a complete image with all its parts requires a lower effort of imagination; therefore, the public's ability of interpreting the surviving elements is diminished. This leads to simplified and fast interpretation and to a reduced

\footnotetext{
4 "While computer-based visualisation methods are now employed in a wide range of contexts to assist in the research, communication and preservation of cultural heritage, a set of principles is needed that will ensure that digital heritage visualisation is, and is seen to be, at least as intellectually and technically rigorous as longer established cultural heritage research and communication methods. At the same time, such principles must reflect the distinctive properties of computerbased visualisation technologies and methods". London Charter, 2009, p. 2.

5 "Today, the worldwide application of computer-based visualisation in the field of archaeological heritage may be described as full of "lights and shadows". The spectacular growth of cultural tourism and the amazing technological advances in recent years have led to the development and implementation of a myriad of projects to investigate, preserve, interpret and present various elements of archaeological heritage using computer-based visualisation. These projects have demonstrated not only the extraordinary potential of computer-based visualisation but also its many weaknesses and inconsistencies. Therefore, there is a clear need for a theoretical debate with practical implications to enable heritage managers use the best that new technology can offer them in this area while minimizing its most controversial applications. In short, some basic principles must be established to govern practices in this growing field". Seville Charter, 2011, p. 2.

6 "... with whose work I had become acquainted through Henry Schaefe - Simmern, asserted that the mind in its struggle for an orderly conception of reality proceeds in a lawful and logical way from the perceptually simplest patterns to patterns of increasing complexity." Arnheim 1954, p. 6.
} 
observation time having as a consequence fast fruition and reduced critical investigation.

Though the reconstruction hypotheses are the result of an interdisciplinary work among the various professionals who interpret all the surviving findings with scientific rigor. Anyway, this does not eliminate the errors of interpretation due to the fact that each person gathers information according to his/her own experiences. Therefore, virtual reconstructions are interpretations of the ancient time made by a certain group of people with the tools available in their time. Even the most rigorous reconstructions are an interpretation made in our time starting from the state of conservation of an artefact ${ }^{7}$. One of the fundamental problems of reconstructions is that they cannot be considered univocal, but will always be relative, because different people using the same means, information and scientific rigour might produce an image which has completely different colour and proportion ratios. Therefore, it would be preferred to have models that show the original information and data. Alternative solutions are to be suggested rather than the solution of only one reconstruction.

"Nonetheless, it should be pointed out that even the worst reconstruction does, in fact, document human activity, albeit mistakenly, and that it is still part of human history. Therefore, it should not be removed-at the most it may be isolated." Brandi [1963] 1977, quoted from the English translation 2005, p. 69. 


\section{Bibliography}

Arnheim, R. (Ed.) (1954). Art and Visual Perception. A Psychology of the Creative Eye. Berkeley and Los Angeles: University of California.

Brandi, C. (1963). Teoria del restauro: lezioni raccolte da L. Vlad. Borrelli, J. Raspi Serra, G. Urbani ... Con una bibliografia generale dell'autore. Roma: Edizioni di Storia e letteratura.

Brandi, C. (1977). Teoria del restauro. Torino: Giulio Einaudi Editore - Piccola Biblioteca Einaudi Ns. Brandi, C. (2005). Theory of Restoration. Edited by Giuseppe Basile and the Istituto Centrale per il Restauro, translated by Cynthia Rockwell. With presentations by Giuliano Urbani, Nicholas StanleyPrice, Caterina Bon Valsassina, with texts by Giuseppe Basile, Paul Philippot, Giulio Carlo Argan, Cesare Brandi. Firenze: Nardini editore.

Cornell, R. M \& Schwertmann, U. (1996). The iron oxides: structure, properties, reactions, occurrence, and uses (p. 29 ). New York: WILEY-VCH.

Eastaugh, N., Walsh, V., Chaplin, T. \& Siddall, R. (Eds.) (2004). The Pigment Compendium. (p.201). Oxford: Elsevier Butterworth-Heinemann.

Forte, M. \& Beltrami, R. (2000). A proposito di virtual Archaeology: disordini, interazioni cognitive virtualitá. In: Archeologia e Calcolatori n. XI, Moscati, P. (Ed.), pp. 273-300.

Forte, M. (2008). Virtual archaeology. Communication in 3D and ecological thinking. In: Beyond Illustration: 2D and 3D Digital Technologies as Tools for Discovery. In: Archaeology, ArcheoPress, Oxford, pp. 20- 34 .

Foti, G. (1969, October). Lattività archeologica in Calabria. In: La Magna Grecia nel mondo ellenistico, IX(LIV), Taranto, pp. 166-171.

Gombrich, E. (1982). The Image and the Eye. Further Studies in the Psychology of Pictorial Representation. Oxford: Phaidon.

Guzzo, G. (1971, Sept./Oct.). III campagna di scavi nella piana del Crati. In: Magna Grecia, anno VI, nr. 9-10, Taranto, pp. 21-24.

Guzzo, G. (1972, October). La documentazione archeologica in Calabria. In: Magna Grecia, XII(LIV), Taranto, pp. 341-345.

Limoncelli, M. (2012). Il progetto "Hierapolis Virtuale" esperienze di restauro virtuale e restituzione in 3D. In: D'Andria, R. \& Mannino, K. (Eds.). Gli allievi raccontano (pp.247-253). Galatina: Congedo. Lopez-Menchero Bendicho V. M. \& Flores Gutierrez, M. \& Vincent, M. L. \& Grande Leon, A. (2017). Digital Heritage and Virtual Archaeology: An Approach Through the Framework of International Recommendations. In: E Levy, T (Ed.). Digital Heritage and Virtual Archaeology in the Digital Age: Acquisition, Curation, and Dissemination of Spatial Cultural Heritage Data (p. 594). Murcia: Springer Verlag.

Rossi Pinelli, O. (2005). Verso un'immagine integrale: derestauri e rirestauri nelle esperienza contemporanee. In: Piva. C \& Sgarbozza, I. (Eds.). Il corpo dello stile (pp. 119-134). Roma: De Luca Editori d'Arte. 
Settis, S. (2002). L'illusione dei beni digitali. In: Bollettino ICR-Nuova serie, N. 5, (pp. 18-20). Firenze: Nardini Editore.

\section{Sitography}

King's College London (7 Febrary 2009): The London Charter. Retrived from http//www.londoncharter. org

International Forum Of Virtual Archaeology (2011): The Seville Principles. Retrived from http:// www.arqueologiavirtual.com/carta 
